\title{
Peran Expert Endorser dalam Menyampaikan Informasi Rumah Syariah (Studi Kasus: Syeikh Ali Jaber pada Kampung Tahfidz Jatiluhur)
}

\author{
Dzaky Hasyim, Janette Maria Pinariya, Priambodo Idris \\ LSPR Communication and Business Institute \\ Email:dzkyhsym@gmail.com
}

DOI: https://doi.org/10.21107/ilkom.v14i2.8211

\begin{abstract}
ABSTRAK
Penelitian ini membahas peran ulama sebagai expert endorser dalam menyampaikan informasi mengenai rumah berbasis syariah. Hal ini dilandasi oleh ketertarikan peneliti karena adanya peningkatan 11,23 persen pada jumlah pembelian properti melalui sistem syariah. Tercatat bahwa Indonesia memiliki urutan negara ke 10 menurut Global Islamic Finance Development Indicator (IFDI) 2018 sebagai The Most Developed Islamic Finances Markets dari 131 negara di dunia. Para praktisi menilai, peluang ekonomi berdasarkan syariah dapat berpotensi untuk dikembangkan di Indonesia. Strategi pemasaran melalui media sosial seperti youtube dengan menggunakan model endorse menjadi trend baru saat ini. Objek dalam penelitian ini adalah Kampung Tahfidz Jatiluhur merupakan salah satu properti yang menggunakan konsep syariah dalam transaksi jual beli nya dan Syeikh Ali Jaber sebagai expert endorser. Metode penelitian yang digunakan dalam penelitian ini adalah metode penelitian kualitatif deskriptif dengan menggunakan source model theory untuk menganalisis dan menginterpretasi expert endorser. Dalam pencarian data penelitian ini menggunakan wawancara dengan 5 informan. Dalam tahap penelitian, peneliti mengklasifikasi dan mengidentifikasi berdasarkan elemen-elemen source model theory setelah dihubungkan antara expert endorser dengan source model theory. Hasil penelitian menyimpulkan bahwa expert endorser yang memiliki credibility dan attractiveness yang baik akan memberikan pemahaman yang baik mengenai produk maupun jasa, sehingga hal ini dapat meningkatkan daya tarik dari Kampung Tahfidz Jatiluhu.
\end{abstract}

Kata kunci : attractiveness, credibility, expert endorser, riba, rumah syariah, source model theory

\section{ABSTRACT}

This study discusses the role of supporting experts in discussing information about sharia-based homes. This is based on the interest of researchers because of an 11.23 percent increase in the number of property purchases through the sharia system. It was noted that Indonesia has ranked 10th country according to the 2018 Global Islamic Financial Development Indicator (IFDI) as the Most Developing Islamic Financial Market out of 131 countries in the world. Obtaining approval, economic opportunities based on sharia can be increased to be developed in Indonesia. marketing strategies through social media like youtube by using supportive models to become a new trend nowadays. The object in this study is Tahfidz Jatiluhur Village which is one of the properties that uses the concept of sharia in its sale and purchase transactions and Shaykh Ali Jaber as an expert endorser. The research method used in this research is descriptive qualitative research method using the source model theory to analyze and interpret supporting experts. In searching for data this study used interviews with 5 informants. In research, research classifies and studies the elements of source model theory after being discussed between endorser experts and source model theory. The results of the study concluded that expert endorsers who have good credibility and attractiveness will provide a good understanding of products and services, so that this can increase the attractiveness of Kampung Tahfidz Jatiluhur.

Keywords : attractiveness, credibility, expert endorser, source model theory, syariah house, riba

\section{Cite this as :}

Hasyim, D., Pinariya, J.M., Idris., P. (2020). Peran Expert Endorser dalam Menyampaikan Informasi Rumah Syariah (Studi Kasus: Syeikh Ali Jaber pada Kampung Tahfidz Jatiluhur). Jurnal Komunikasi, 14(2), 161-172. doi: https://doi.org/10.21107/ilkom.v14i2.8211

Article History:

Received August, $11^{\text {th }} 2020$,

Acepted September, $3^{\text {th }} 2020$ 


\section{PENDAHULUAN}

Beberapa tahun belakangan bisnis properti syariah tumbuh dengan signifikan. Menurut data Thomson Reuters (2018) dari Otoritas Jasa Keuangan (OJK) adanya peningkatan 11,23 persen pada jumlah pembelian properti melalui sistem syariah. Para praktisi menilai, peluang ekonomi berdasarkan syariah dapat berpotensi untuk dikembangkan di Indonesia karena berdasarkan fakta bahwa Indonesia merupakan negara yang memiliki komunitas muslim terbesar di dunia. Tercatat bahwa Indonesia memiliki urutan negara ke 10 pada Global Islamic Finance Development Indicator (IFDI) 2018 sebagai The Most Developed Islamic Finances Markets dari 131 negara di dunia.

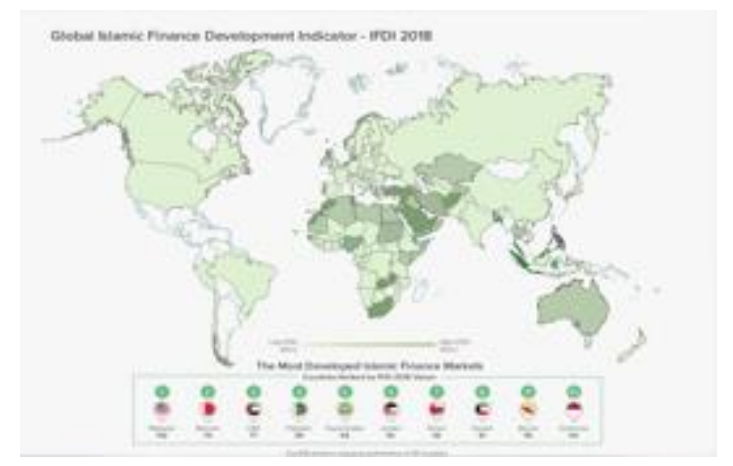

Gambar 1. The Most Developed Islamic

Finances Markets dari 131 negara di dunia, Islamic Finance Development Indicator (IFDI) 2018, (Thomson Reuters, 2018)

Pertumbuhan properti dari tahun ke tahun memiliki catatan mencapai 48,30\%. Menurut Country General Manager Rumah123 Ignatius Untung, menyatakan bahwa peningkatan penjualan properti masih naik tahun ini 2,8 persen dari GDP (Produk Domestik Bruto) (Hamdi, 2017).

Syariah bisa menjadi peluang dalam berbisnis properti khususnya di Indonesia karena masyarakat muslim cukup banyak namun developer perumahan yang sistem pembayarannya syariah atau non-kpr kurang banyak. Padahal di Indonesia mayoritas masyarakatnya menganut agama islam dan menjunjung tinggi aturan-aturan yang ada di dalam agama tersebut.

Properti syariah yaitu properti yang menggunakan metode transaksi secara syariah yang sesuai dengan nilai-nilai dari agama Islam. Target marketnya tidak hanya masyarakat yang beragama Islam saja melainkan orang yang beragama non-Islam pun boleh untuk membeli rumah ini. Ada beberapa pemikiran yang diterapkan dalam konsep syariah yaitu tidak ada riba, tidak ada denda, tidak ada sita dan tidak menggunakan bank (Khoirunisa, 2016). Informan Deny menyebutkan bahwa properti syariah adalah bisnis properti yang sesuai dengan Al Quran dan hadist. Dimana properti ini bebas dari 3 hal yaitu mesyir, ghoror, riba. Selain itu pada transaksi sebenarnya bisa dan diperbolehkan menggunakan bank syariah, namun saat ini di benak masyarakat properti syariah itu tidak menggunakan bank.

Kampung Tahfidz Jatiluhur memiliki konsep yang Islami mewajibkan penghuninya muslim sehingga mempunyai ide keinginan jalan yang sama dan bisa hidup bersama sama dengan baik agar tercapainya ketaqwaan itulah yang dimaksud konsep syariah. Hal ini serupa dengan sistem syariah Kampung Tahfidz Jatiluhur, skema kontan bertahap dan skema kontan keras untuk pembayaran, karena Kampung Tahfidz Jatiluhur bukan perusahan riba jadi sistem penagihannya tidak seperti debt collector. Rumah atau properti dengan konsep syariah berarti harus memiliki elemen syariah seperti yang di katakan oleh (Ali \& Hasan, 2014) yaitu pertama perlindungan diri (atau kehidupan), kedua perlindungan iman, ketiga perlindungan kekayaan, ke empat perlindungan intelektual, kelima perlindungan keturunan. Yang bertujuan untuk membimbing manusia agar mereka berhasil, secara individu dan secara bersama sama untuk menyelamatkan dari kegagalan besar atau kerugian besar di dunia maupun di akhirat.

Menurut Fatwa MUI (Majelis Ulama Indonesia) Nomer 1 Tahun 2004 menyatakan bahwa pengertian bunga adalah tambahan yang dikenakan dalam transaksi pinjaman 
uang yang diperhitungkan dari pokok pinjaman tanpa mempertimbangkan pemanfaatan atau hasil pokok tersebut, berdasarkan tempo waktu, diperhitungkan secara pasti di muka, dan pada umumnya berdasarkan persentase. Riba adalah tambahan tanpa imbalan yang terjadi karena penangguhan dalam pembayaran yang dijanjikan sebelumnya, Dan inilah yang disebut riba nasi'ah.s. Dengan demikian hukum bunga atau praktek pembungaan uang termasuk salah satu bentuk riba, dan riba haram hukumnyas (Indonesia, 2004, hal. 434)

Trend marketing syariah di Indonesia banyak diminati oleh masyarakat dengan memberikan kualitas yang baik sehingga banyak orang yang mencarinya. Hal ini memberikan potensi yang memang besar kepada perkembangan bisnis syariah di Indonesia (Fauzian, 2020). Dalam brosur maupun media promosi lainnya terdapat informasi bahwa tidak adanya riba di dalam transaksi maupun konsep Kampung Tahfidz Jatiluhur karena didalamnya terdapat system syariah yang berdasarkan nilai-nilai dari agama Islam.

Dilansir dari website yang berfokus pada sektor keuangan menyatakan bahwa Didalam Agama Islam, Riba secara bahasa bermakna tambahan atau meminta kelebihan uang dari nilai awal. Secara lebih spesifik riba adalah meminta tambahan uang dari pinjaman awal baik dalam transaksi jual beli maupun pinjam meminjam yang bertentangan dengan prinsip syariah Islam. Ada beberapa pemikiran yang diterapkan dalam konsep syariah yaitu tidak ada riba, tidak ada denda, tidak ada sita dan tidak menggunakan bank (Khoirunisa, 2016). Meskipun mayoritas penduduk Indonesia adalah beragama Islam, tetapi pengembangan properti syariah berjalan lambat dan belum berkembang seperti data di bawah ini data penjualan pada Kampung Tahfidz Jatiluhur pada tahun 2018 (Kampung Tahfidz Jatiluhur, n,d)

Hal ini disebabkan karena masih kurangnya masyarakat memahami akan tentang pembiayaan syariah termasuk untuk dalam sistem syariah pembiayaan rumah dan mungkin bisa menyebabkan masih banyak orang enggan menggunakan pembiayaan syariah untuk KPR (Aditiasari, 2016)

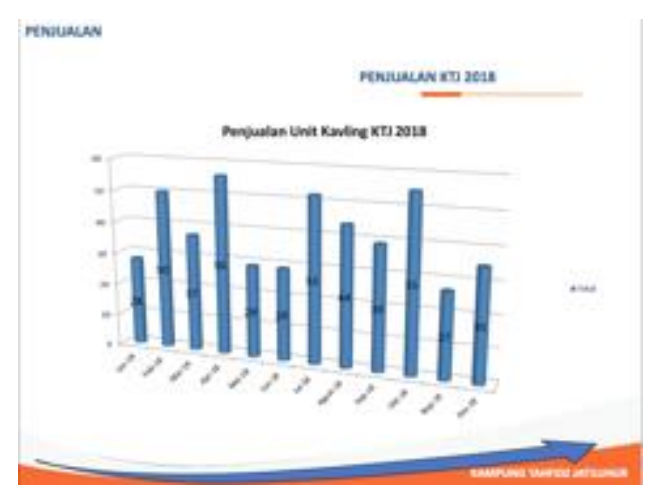

Gambar 2. Data penjualan pada Kampung Tahfidz Jatiluhur pada tahun 2018, dari Company Profile Kampung Tahfidz Jatiluhur 2019.

$\begin{array}{ccc}\text { Kampung } & \text { Tahfidz Jatiluhur } \\ \text { merupakan salah satu properti yang }\end{array}$ menggunakan konsep syariah dalam transaksi jual beli nya. Selain itu di dalam kawasan Kampung Tahfidz Jatiluhur ini tidak hanya menjual properti seperti hunian saja tetapi menjual juga kavling kebun buah. Salah satu cara perusahaan ini menyampaikan komunikasi persuasif yaitu dengan cara menggunakan expert endorser dimana, yang bisa dibilang salah satu tokoh umat muslim yang dikenal di Indonesia maupun Internasional yaitu Syeikh Ali Jaber. Beliau yang nantinya menjadi penasehat di dalam pembangunan pesantren yang ada di Kampung Tahfidz Jatiluhur. (Kampung Tahfidz Jatiluhur, n,d)

Ali Soleh Mohammed Ali Jaber yang sering dikenal dengan nama Syeikh Ali Jaber ini adalah seorang tokoh ulama asal Madinah Arab Saudi yang saat ini tinggal di Indonesia. Beliau seorang imam di masjid Nabawi, Pendakwah dan Ulama berkewarganegaraan Indonesia. Beliau juga pernah menjadi juri pada Hafiz Indonesia. Syekh Ali Jaber mengawali kegiatan dakwah di Indonesia di tahun 2008, hal itu didukung dengan menikahi seorang gadis asli Lombok, Indonesia, 
bernama Umi Nadia yang sudah lama tinggal di Madinah (Viva.co.id, n.d.)

Jokowi mengatakan bahwa Indonesia adalah sebagai negara masyarakat muslim terbesar di dunia. Kekuatan Indonesia sebagai negara muslim dapat menjadi modal besar dalam upaya diplomasi. (Berty, 2019). Tetapi tidak hanya faktor agama saja yang mempengaruhi perilaku masyarakat terhadap keputusan pembelian. Banyak faktor lain diduga juga dapat mempengaruhi interaksi masyarakat terhadap dunia properti. Dengan memahami persepsi masyarakat terhadap properti tersebut, maka perumahan syariah atau konvensional memiliki perbedaan yang kuat untuk membuat strategi dan kebijakan agar lebih menjual ke masyarakat

Di era perdagangan bebas, kompetisi terbuka lebar antara pelaku bisnis. Kompetisi tersebut menjadi kendala dalam kegiatan bisnis, yang bisa diatasi dengan kegiatan komunikasi pemasaran yang baik. Meningkatnya ekonomi kreatif dan ekonomi digital di era 4.0, strategi pemasaran melalui media sosial seperti instagram dengan menggunakan model endorse menjadi trend baru (Christiawan, 2019). Komunikasi bisnis yaitu wujud dari komunikasi yang berfokus pada aktivitas bisnis, yang sering melibatkan komunikasi antar pribadi, komunikasi organisasi sekaligus komunikasi pemasaran. Bertujuan untuk menyampaikan pesan bisnis yang dibuat oleh komunikator kepada penerima pesannya, hal yang terpenting disini adalah untuk mempersuasi (Molyo, 2016).

Menurut (Suherman, 2016) menjadi endorser seperti menjadi ikon atau sosok tertentu yang juga disebut sebagai direct source. Mereka sumber langsung untuk mengantarkan sebuah pesan, memperagakan sebuah produk atau jasa dalam kegiatan promosi. Brand endorsement merupakan social media promotion yang tidak sulit dilakukan, namun tidak bisa juga dilakukan secara asal-asalan. Sebagai contoh tidak mungkin kita memilih Christiano Ronaldo untuk produk kecantikan wanita. Dengan begitu perusahaan harus cermat memilih endorser yang tepat, mempunyai followers yang sesuai dengan segmen dan target market produk atau jasa yang ingin dipromosikan (Sindonews.com, 2015).I

Dengan menerapkan sistem endorsement secara benar, kredibilitas atau keaslian kualitas suatu produk atau jasa akan lebih dipercaya sehingga bisa menaikkan brand awareness, brand exposure, dan berujung pada peningkatan penjualan itu sendiri (Sindonews.com, 2015). Marketing saat ini tidak lagi dipandang hanya sekedar tentang penyaluran barang dan jasa dari produsen kepada konsumen yang menjadikan media dalam memberikan informasi mengenai sesuatu hal seperti hal riba atau syariah yaitu pembelian barang dan jasa yang sesuai dengan hukum Islam dalam Agama Islam. Karena fenomena rumah syariah di Indonesia peneliti tertarik untuk meneliti apakah expert endorser seperti opinion leader umat muslim dapat mempengaruhi masyarakat dalam meningkatkan awareness mengenai pemahaman rumah syariah.

\section{METODE PENELITIAN}

Penelitian dilakukan dari bulan September 2018 sampai dengan Juni 2019, bertepatan di Provinsi DKI Jakarta. Metode penelitian yang digunakan dalam penelitian ini adalah kualitatif deskriptif. Penelitian Kualitatif menurut (Afrizal, 2016, p. 13) adalah metode penelitian ilmu sosial dengan mengumpulkan dan menganalisa data berupa kata-kata (lisan maupun tulisan) dan tingkah laku manusia serta peneliti tidak berusaha menghitung atau mengkuantifikasikan data kualitatif yang telah diperoleh dan dengan demikian tidak menganalisis angka-angka.

Konstruktivisme sosial bahwa individu mencari pemahaman tentang dunia tempat mereka tinggal dan bekerja, tujuannya untuk mengandalkan sebanyak mungkin pandangan partisipan tentang situasi yang sedang dipelajari (Cresswell, 2014).

Penelitian ini menggunakan metode kualitatif yang mana menganalisis data deskriptif untuk melihat perilaku masyarakat 
didalam marketing Syariah. Pengumpulan data dilakukan melalui wawancara semiterstruktur mewawancarai enam narasumber yang terlibat aktif dalam komunikasi yang terjadi di dalam Kampung Tahfidz Jatiluhur. Dalam penelitian ini, peneliti mewawancarai enam narasumber terdiri dari Ibnu Hadjar (owner), Januar Timbuleng (management representative Kampung Tahfidz Jatiluhur), Usep Saepulloh costumer Kampung Tahfidz Jatiluhur, Fajar Munich calon costumer Kampung Tahfidz Jatiluhur yang terlibat aktif dalam komunikasi yang terjadi di dalam Kampung Tahfidz Jatiluhur dan Deny Heryadi dewan pengawas syariah koperasi karyawan Bridgestone sebagai pakar ahli syariah.

Proses teknik analisis data dilakukan dengan menggunakan studi Miles and Huberman (1994) yang terdiri dari pengumpulan data, penyajian data, reduksi data dan verifikasi data. Setelah teknik analisis data dilakukan, peneliti perlu menguji kredibilitas data melalui triangulasi. Konsep triangulasi ini diartikan sebagai teknik pengecekan data dari berbagai sumber, cara dan waktu yang dilakukan peneliti. Teknik pemeriksaan kepercayaan atau kredibilitas dalam penelitian ini adalah menggunakan teknik kepercayaan Triangulasi data. Karena di penelitian ini peneliti mencari data dari beberapa sumber yang berbeda background (Sugiyono, 2016).

\section{HASIL DAN PEMBAHASAN}

Kebutuhan masyarakat mengenai properti semakin meningkat karena seiring meningkatnya pertambahan jumlah penduduk. Kebutuhan masyarakat akan properti yang bernuansa syariah dimana dalam transaksinya terhindar dari unsur riba dan konsep kampung tahfidz ini yang dijadikan sebagai komunitas muslim yang akan menuntun mereka, mengajar mereka untuk memiliki lingkungan yang islami yang sesuai dengan syariat Islam, sehingga mereka bisa mengambil manfaatnya.
Ibnu Hadjar berharap Kampung Tahfidz Jatiluhur tumbuh dan bisa mewujudkan cita-citanya dan rencananya menjadi kawasan muslim dimana semua penghuninya muslim yang taat dari seluruh indonesia dan tidak ada perbedaan, semuanya sama sehingga bisa membantu mewujudkan keinginan umat muslim agar bisa investasi dan membantu menghasilkan secara ekonomi mereka dari kebun yang dimiliki. kedua mereka mempunyai tempat tinggal atau tempat berlabuh yang nyaman sesuai syariah dan mereka punya fasilitas pendidikan untuk anak anaknya dan keluarga yang berada di lingkungan yang Islami sehingga mereka bahagia secara dunia dan selamat juga di akhirat.

Tidak hanya itu, Januar selaku manajemen representatif Kampung Tahfidz Jatiluhur berharap kedepannya Kampung Tahfidz Jatiluhur dapat mewujudkan mimpi umat Islam yaitu sebagai hunian muslim terbesar di jawa barat bahkan Indonesia selain itu terdapat kawasan pendidikan yaitu pesantren, kawasan agrowisata, agro industri dan semua wisata sehingga umat muslim dapat berkumpul disana (Komunikasi Pribadi, Januar).
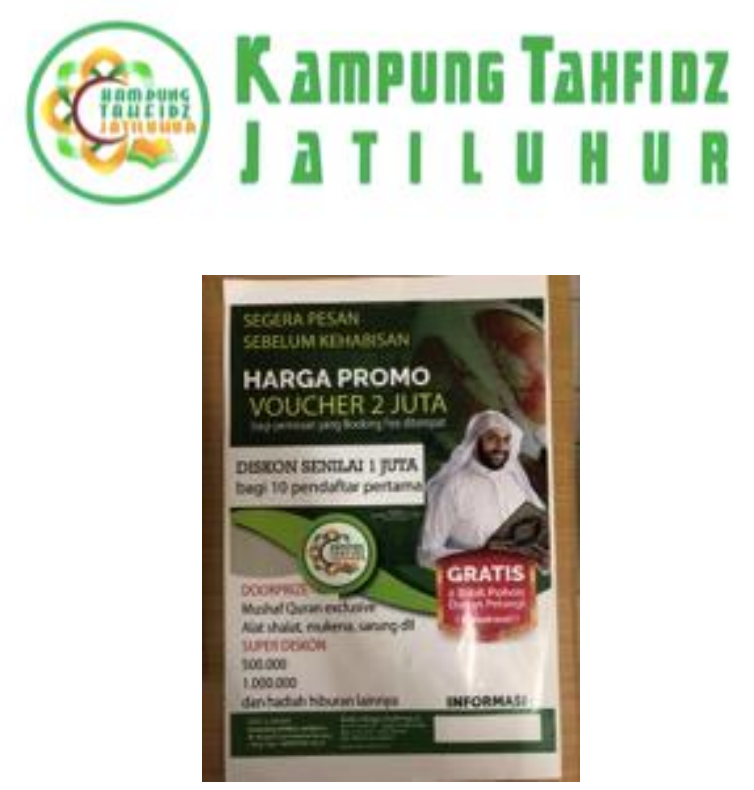

Gambar 3. Logo Kampung Tahfidz Jatiluhur dan Brosur Kampung Tahfidz Jatiluhur (data pribadi, 2019) 
Dalam melakukan strategi pemasaran, Kampung Tahfidz Jatiluhur salah satunya menggunakan seorang expert endorser seorang ulama yang cukup dikenal di Indonesia yaitu Syeikh Ali Jaber. Ibnu menyatakan alasannya mengajak Syeikh Ali Jaber sebagai expert endorser karena kapasitas beliau sebagai ulama dan banyak jamaahnya, sehingga beliau bisa menjadi pembina dan dapat meyakinkan bahwa produk Kampung Tahfidz Jatiluhur sesuai dengan syariat. Hal ini dapat memberikan dorongan nilai jual dari produk yang ditawarkan sehingga bisa mendongkrak penjualan Kampung Tahfidz Jatiluhur.

Ohanian (1990) menyatakan keefektifan pesan tergantung pada persepsi kredibilitas, keahlian dan daya tarik yang dimiliki endorser melalui membangun kredibilitas endorser. Menurut Clow, (dalam Pinariya \& Pracillia, 2014), mengatakan bahwa perusahaan menggunakan pendukung selebritas ketika cap persetujuan orang tersebut meningkatkan ekuitas merek produk. Selebriti juga dapat membantu menciptakan ikatan emosional dengan merek. Mentransfer ikatan yang ada antara selebriti dan audiens ke produk yang disahkan adalah tujuannya. Untuk melihat persepsi kredibilitas, keahlian dan daya tarik peneliti menggunakan source model theory yang memiliki 2 elemen yaitu source credibility dan source attractiveness.

Expert endorser dalam hal ini berarti Syeikh Ali Jaber berarti harus memiliki keahlian yang dapat divalidasi oleh penerima pesan yaitu target market dari Kampung Tahfidz Jatiluhur. Seperti yang diungkapkan tiga narasumber dalam penelitian ini. Pertama diungkapkan oleh Ibnu Hadjar yang mengungkapkan bahwa Syeikh Ali Jaber memiliki keahlian di dalam hal properti berbasis syariah.

Dari pernyataan diatas dapat diartikan bahwa Syekh Ali Jaber memiliki kredibilitas karena pernah juga menjadi expert endorser di property Madinah City. Maka dari itu Kampung Tahfidz Jatiluhur mengajak Syeikh Ali Jaber untuk menjadi expert endorser. Menurut Fajar, Syeikh Ali Jaber memiliki keahlian dan kredibilitas sebagai ulama yang bergerak pada tahfidz Al Quran. Karena itu beliau pantas untuk dipercayai dalam konteks properti maupun rumah syariah. Dari pernyataan diatas dapat diartikan bahwa Syekh Ali Jaber sudah memberikan informasi mengenai peruntukan dari property yang berkonsep syariah, namun tidak ada penjelasan secara lebih detail mengenai konsep syariah itu sendiri dari tata cara ataupun pemahaman selain cara pembiayaan. karena menurut Fajar analogi properti syariah adalah dari cara pembiayaan pembangunan properti berbasis syariah. Sehingga Fajar tidak tahu apakah Syeikh Ali Jaber memiliki keahlian di dalam bidang tersebut.

Hasil wawancara dengan Usep (costumer Kampung Tahfidz Jatiluhur) dan Deny Heryadi (pakar ahli Syariah) membenarkan bahwa melihat sosok Syeikh Ali Jaber memiliki kredibilitas dalam properti Syariah, namun belum tentu beliau ahli fikih muamalah selain itu kredibilitas Syeikh Ali Jaber adalah sebagai sosok seorang ulama dengan kharismatik yang dimiliki.

\section{Source Credibility}

Menurut Biswas et al (2006 : 18) menjelaskan mengenai source model theory adalah kombinasi dari dua theory yaitu source credibility theory dan source attractiveness theory sedangkan menurut Grant (dalam Pinariya \& Pracillia, 2014) berpendapat bahwa sebuah pesan bergantung pada keefektifannya keahliannya (expertness) dan kelayakan kepercayaan (truth worthiness) dari sumbernya. Model hovland menjelaskan bahwa kemampuan diartikan pada sumber yang menunjukkan keahlian dan kepercayaan dapat di artikan kelayakan kebenaran yang dapat dipercaya.

Lafferty et al (dalam Pinariya \& Pracillia, 2014), menyatakan bahwa selebriti biasanya dikaitkan atau dihubungkan dengan kesamaan antara endorser dan jenis produk yang didukung. Expertness (Keahlian) yang diartikan sebagai kemampuan yang dirasakan sumber untuk membuat pernyataan yang 
valid. Kepercayaan (truth worthiness) dapat didefinisikan sebagai kesediaan yang dirasakan dari sumber untuk membuat pernyataan yang valid.

McGuire (dalam Biswas et al., 2006), menyatakan bahwa sumber yang menarik atau source attractiveness secara tradisional dilihat memiliki tiga hal yang saling terkait yaitu familiarity (keakraban), similarity (kesamaan), dan liking (kesukaan).

\section{Expertness (Keahlian)}

Menurut Mccracken dalam (Pinariya \& Pracillia, 2014), Expertness atau keahlian adalah kemampuan yang dirasakan sumber untuk membuat pernyataan yang valid. Model hovland berpendapat bahwa sumber-sumber yang menunjukkan keahlian dan kelayakan kebenaran dapat dipercaya dan sejauh ini persuasif.

Berdasarkan hasil penelitian ini Syeikh Ali Jaber adalah sebagai expert endorser dari Kampung Tahfidz Jatiluhur yang bertugas untuk menyampaikan informasi mengenai Kampung Tahfidz Jatiluhur dan mengajak masyarakat untuk mempunyai properti syariah, hal ini ada di beberapa konten brosur maupun video antara dan Syeikh Ali Jaber dan Kampung Tahfidz Jatiluhur.

Syeikh Ali Jaber memiliki kredibilitas karena dia sebagai orang yang ahli agama, dikenal sebagai ulama dan sering tampil juga dalam publik media sosial dan televisi, dan punya kapasitas sebagai ulama dia mengerti dengan properti syariah, baik secara aturannya, transaksi jual belinya muamalahnya, ataupun konsep perumahannya, jadi perumahan syariah itu seperti apa dan konsep jual belinya seperti apa beliau mengerti.

Selain itu Syekh Ali Jaber sudah memberikan informasi mengenai peruntukan dari property yang berkonsep syariah, namun tidak ada penjelasan secara lebih detail mengenai konsep syariah itu sendiri dari tatacara ataupun pemahaman selain cara pembiayaan. Karena analogi properti syariah adalah dari cara pembiayaan pembangunan properti berbasis syariah.

\section{Truth worthiness (Kelayakan kepercayaan)}

Grant (dalam Hovland, 1989) Truth worthiness (Kelayakan kepercayaan) dapat didefinisikan sebagai kesediaan yang dirasakan dari sumber untuk membuat pernyataan yang valid. Lafferty, Goldsmith, dan Flynn, (2005: 34) menyatakan bahwa selebriti biasanya dikaitkan atau dihubungkan dengan kesamaan antara endorser dan jenis produk yang didukung (Pinariya \& Pracillia, 2014)

Menurut Ibnu Hadjar yaitu owner dari Kampung Tahfidz Jatiluhur, Syeikh Ali Jaber dalam menjelaskan informasi mengenai konsep syariah menggunakan dasar dalil, ayat Al Quran dan hadist-hadist Nabi yang memberikan kepercayaan. Selain itu kadar keilmuwannya dari Syeikh Ali Jaber yang membuat Ibnu semakin percaya dengan setiap perkataan Syeikh Ali Jaber dalam menyampaikan konsep syariah.

Dalam hal ini pengalaman dari seorang sumber menjadi faktor penting saat penerima pesan dalam melakukan validasi perkataan. Selain itu pesona, daya tarik dan kepribadian dari seorang Ulama disini yaitu Syeikh Ali Jaber dapat meyakinkan calon pembeli dari Kampung Tahfidz Jatiluhur. Selain faktor ulama, ternyata ketulusan dan kesamaan visi untuk menciptakan 1 juta penghafal Al Quran dan membentuk komunitas muslim juga menimbulkan kelayakan kepercayaan antara costumer dan Syeikh Ali Jaber sebagai expert endorser di Kampung Tahfidz Jatiluhur.

\section{Source Attractiveness}

McGuire dalam Biswas et al., (2006) menyatakan bahwa sumber yang menarik atau source attractiveness secara tradisional dapat dilihat memiliki tiga hal yang saling terkait yaitu keakraban (familiarity), kesamaan (similarity), dan kesukaan (liking). 


\section{Familiarity}

Keakraban didefinisikan sebagai pengetahuan sumber melalui ekspresi (Biswas et al., 2006). Ekspresi di sini dapat diartikan apakah sumber dikenal atau tidak dikenalnya oleh target market. Menurut Januar dan Deny bahwa Syeikh Ali Jaber sering muncul di acara televisi dan di youtube. Selain itu setiap Kampung Tahfidz Jatiluhur membuat acara gathering pasti selalu ramai. Dengan begitu, Hal ini membuat Syeikh Ali Jaber dikenal oleh sebagian masyarakat luas, namun tidak seluruh masyarakat muslim mengenali Syeikh Ali Jaber.

\section{Similiarity}

Kesamaan yang dimiliki antara sumber dan penerima pesan itulah yang dimaksud dari similiarity (Biswas et al., 2006). Persamaan bisa dalam berbagai macam hal dari kepribadian, pemikiran, atau yang lainnya yang membuat ketertarikan antara penerima pesan dan sumber. Menurut hasil penelitian bahwa Kampung Tahfidz Jatiluhur memiliki target market yaitu masyarakat muslim, karena persyaratan utamanya adalah yang beragama islam. Hal ini bertujuan untuk menjauhi atau menghindari hal hal yang tidak sejalan, karena tujuan dibuatnya Kampung Tahfidz Jatiluhur salah satunya adalah agar ide keinginan jalan yang sama, dan bisa hidup bersama sama dengan menjalankan syariat agama dan tercapainya ketaqwaan bagi seorang muslim. Dalam hal ini Syeikh Ali Jaber memiliki kesamaan yaitu sebagai tokoh ulama yang memiliki tujuan yang sama. Untuk mewujudkan generasi penghafal $\mathrm{Al}$ Quran dan menjadi pertemuan dan perkumpulan keluarga $\mathrm{Al}$ Quran dengan bisnis yang syariah. Selain itu kesamaan antara Syeikh Ali Jaber dengan target marketnya adalah kesamaan visi dan misi dari umat muslim. keberhasilan penyampaian sebuah informasi mengenai syariah oleh Syeikh Ali Jaber yaitu ketika penerima pesan atau audiens menganalisis dan mengartikan pesan yang disampaikan oleh Syeikh Ali Jaber atau video konten yang di buat oleh Kampung
Tahfidz Jatiluhur. Karena setiap individu pasti memiliki pemahaman dan intelektual yang berbeda yang menyebabkan perbedaan apabila tidak sama pemahamannya. Selain itu konsep yang ditawarkan menarik minat Usep untuk membeli rumah atau kavling di Kampung Tahfidz Jatiluhur.

Dengan kesamaan dan melihat lingkungan yang kondusif sesuai dengan keinginan Usep sehingga beliau berkeinginan dan akhirnya untuk membeli rumah syariah di Kampung Tahfidz Jatiluhur. Hal ini berarti kesamaan mengenai produk dan dan expert endorser yaitu Syeikh Ali Jaber dalam mempromosikan Kampung Tahfidz Jatiluhur dapat meningkatkan interest atau keinginan target market untuk memiliki hunian atau investasi di Kampung Tahfidz Jatiluhur.

\section{Likebility}

Likability adalah daya tarik sumber seperti fisik, perilaku, motivasi, atau kepercayaan dari sumber (Biswas et al., 2006). Daya tarik disini akan mendukung terjadinya ketertarikan terhadap sumber dan menghasilkan keefektifan pesan yang akan disampaikan. Daya tarik Syeikh Ali Jaber menurut Ibnu Hadjar yaitu dari sisi mengajak masyarakat muslim untuk memiliki atau membeli properti yang syariah baik secara lisan saat berdakwah di acara gathering pertemuan dengan para calon pembeli maupun konten video yang beliau upload di youtube.

Tetapi ternyata strategi Kampung Tahfidz Jatiluhur untuk memperkuat daya tarik dan ajakan dorongan masyarakat agar membeli dan memiliki hunian atau investasi di Kampung Tahfidz Jatiluhur selain ulama syeikh ali jaber mereka menggandeng ulama lain seperti ustadz Amir Faisol untuk mendampingi. Sehingga semua bisa menjadi perbandingan bahwa tidak hanya satu ulama yang mengajak kita untuk berperilaku syariah di Kampung Tahfidz Jatiluhur.

Menurut Januar gestur tubuh dan gaya bicara yang dimiliki seseorang juga mempengaruhi daya tarik dari seseorang 
tersebut. Syeikh Ali Jaber yang lahir di tanah arab juga dapat memberikan image beliau sebagai ulama yang dapat menarik massa yang banyak. Terlihat penampilan Syeikh Ali Jaber di dalam acara televisi maupun video dakwah dan video promosi Kampung Tahfidz Jatiluhur yang sedang menggunakan gamis putih panjang dengan sorban.

Tetapi menurut Usep sebagai costumer Kampung Tahfidz Jatiluhur, faktor yang paling besar yang menumbuhkan ketertarikannya dengan Kampung Tahfidz Jatiluhur adalah konsep yang menarik dan bagus. Menurutnya Syeikh Ali Jaber adalah sebagai penguat dari konsep yang di kembangkan oleh Kampung Tahfidz Jatiluhur agar lebih meyakinkan para calon pembeli bahwa konsepnya akan terealisasi dengan baik. Namun sampai saat ini masih ada beberapa orang yang belum ada ketertarikannya dengan property syariah karena ada beberapa faktor yang belum terpenuhi oleh pihak Syeikh Ali Jaber maupun pihak Kampung Tahfidz Jatiluhur dalam menyampaikan informasi mengenai konsep syariah. Fajar mengatakan bahwa ada pengecualian apabila ada penjelasan mengenai sumber pembiayaan dan penjelasan konsep syariah secara mendetail dari pihak Syeikh Ali Jaber maupun pihak Kampung Tahfidz Jatiluhur. Dan menurut Fajar, bahwa Syeikh Ali Jaber adalah bukan sebagai faktor dirinya untuk tertarik membeli hunian syariah di Kampung Tahfidz Jatiluhur.

\section{Expert Endorser}

$$
\text { Clow dalam Soliha }
$$

menyebutkan definisi expert endorser yaitu individu atau kelompok yang memiliki pengetahuan dan informasi yang mendalam terhadap produk yang diiklankannya. Dalam hal ini expert endorser dari Kampung Tahfidz Jatiluhur adalah Syeikh Ali Jaber. Dengan kemampuan yang dimiliki oleh Syeikh Ali Jaber, beliau berperan aktif dalam memberikan informasi mengenai Kampung Tahfidz Jatiluhur. Menurut Usep bahwa Syeikh Ali Jaber merupakan Ulama yang memiliki ilmu mengenai properti syariah. Walaupun sebenarnya Syeikh Ali Jaber lebih spesialis di bidang penghafal Al Quran atau Tahfidz Quran. Karena beliau mempunyai yayasan berbasis dibidang pendidikan $\mathrm{Al}$ Quran, sosial dan dakwah, sesuai dengan pemahaman yang benar agar meningkatkan pengetahuan pada masyarakat Indonesia.

Namun dengan adanya dukungan dari beberapa ustadz - ustadz yang lain dalam pelaksanaannya, hal ini memberikan keyakinan lebih bagi para costumer untuk meyakini bahwa Syeikh Ali Jaber adalah seorang expert di bidang properti syariah. Berarti expert endorser memiliki alasan terkait pada suatu produk, karena kemampuannya mengenai suatu hal, maka expert endorser dapat dijadikan sebagai pedoman masyarakat mengenai suatu hal. Pernyataan ini didukung oleh (Soliha, 2012) yaitu expert endorsement efektif karena sifat komunikasi yang dihasilkan seorang expert endorser lebih disetujui daripada sifat komunikasi yang sama dengan non expert.

Terdapat hasil bahwa Syeikh Ali Jaber memiliki kredibilitas dan memiliki pengikut atau jamaah yang banyak sehingga beliau dapat dipercaya dan dijadikan contoh figur agar bisa menaikkan penjualan Kampung Tahfidz Jatiluhur. Terbukti dari jumlah peserta yang banyak hingga mencapai 10002000 peserta yang hadir dalam acara gathering atau tabligh akbar yang diselenggarakan oleh pihak Kampung Tahfidz Jatiluhur dengan pengisi acara tersebut adalah Syeikh Ali Jaber, dan peserta biasanya didominasi oleh wanita atau ibu-ibu.

\section{Syariah}

Dalam hal ini Kampung Tahfidz Jatiluhur sudah memiliki konsep dari ke 5 elemen dasar syariah yaitu transaksi tidak menggunakan bank konvensional, akan tetapi langsung ke Kampung Tahfidz Jatiluhur. Bisa membayar dengan mencicil langsung tanpa dikenai bunga, atau denda jika terlambat atau disita karena batal membeli bahkan transaksi kita baik dalam bagi hasil pengolahan kebun 
atau transaksi lainnya harus berdasarkan ajaran ajaran dan tata tata syariah.

Hal ini sesuai dengan pernyataan Syed Ali \& Hasan (1435) bahwa masalah-masalah hukum yang secara kritis membahas apa yang boleh dilakukan dan apa yang tidak boleh dilakukan. maka tujuannya adalah untuk memberikan perlindungan terhadap beberapa elemen dasar dari syariah yaitu perlindungan diri (atau kehidupan), iman, kekayaan, intelektual dan keturunan.

Kampung Tahfidz Jatiluhur menjalankan elemen dasar dari syariah yaitu pertama membuat sistem transaksi jual beli ataupun bagi hasil perkebunan yang sesuai dengan konsep syariah. Kedua, membuat konsep lingkungan yang jauh dari hal yang maksiat dan yang dilarang. Ketiga, menciptakan lingkungan yang membuat orang lebih khusyuk lebih dekat kepada agama dan lebih dekat pada ulama. Keempat, berusaha untuk menciptakan kesetaraan dan bimbingan untuk kedepan masyarakat di sekitar Kampung Tahfidz Jatiluhur yang mayoritas muslim dalam hal ekonomi, agama, sosial dan budaya. Kelima, bagi yang memiliki anak kecil bisa menimba ilmu di pesantren di dalam kawasan Kampung Tahfidz Jatiluhur sehingga terciptanya generasi muslim yang baik.

\section{PENUTUP}

Hasil penelitian dapat disimpulkan bahwa Syeikh Ali Jaber yang menjadi expert endorser dianggap sebagai individu yang memiliki tingkat credibility dan attractiveness, yang mana memiliki pengetahuan dan pengalaman untuk dapat memberikan pemahaman serta menjadi daya tarik bagi masyarakat untuk dapat mendorong daya beli suatu produk dan jasa. Peran beliau aktif dalam mempromosikan dan menyampaikan informasi mengenai konsep syariah hal ini memberikan pemahaman yang lebih kepada masyarakat mengenai konsep syariah.

Peneliti memberi masukan untuk 5 elemen dasar syariah yang kurang diinformasikan secara lebih detail kepada masyarakat didalam materi promosi yang dibuat oleh Kampung Tahfidz Jatiluhur. Ada beberapa costumer yang memberikan saran agar sumber pembiayaan dan konsep syariah diinformasikan secara lebih detail. Karena informasi yang detail akan dapat lebih meyakinkan dan memberikan daya tarik lebih costumer pada produk yang ditawarkan.

\section{DAFTAR PUSTAKA}

Afrizal. (2016). Metode Penelitian Kualitatif. Jakarta: Rajawali Pers. Pusat Statistik Indonesia. (2018). Statistical Yearbook of Indonesia

Ali, S. S., \& Hasan, H. (2014, September 22). Towards a Maqasid al-Shariah based Development Index. 1-2. IRTI Working Paper Series. WP\#1435-18. Jeddah, Kingdom of Saudi Arabia : Islamic Research And Training Institue.

AT\&T. (2010). The Big Book of Marketing. (A. G. Bennett, Ed.) The McGraw Hill Companies .

Berty, T. T. (2019, Maret 30). Jokowi: Indonesia Negara Muslim Terbesar, Modal Utama Diplomasi Internasional. Di Akses Pada Juni 10, 2019, DiPeroleh dari Liputan6.com:

https://www.liputan6.com/global/rea d/3930124/jokowi-indonesianegara-muslim-terbesar-modalutama-diplomasi-internasional

Biswas, D., Biswas, A., \& Das, N. (2013, March). The Differential Effects of Celebrity and Expert Endorsments On Consumer Risk Perceptions. Journal of Advertising , 18-19. DOI: 10.1080/00913367.2006.10639231

Bungin, B. (2010). Penelitian Kualitatif. Jakarta: Kencana Prenada Media Group.

Cermati.com. (2016, June 21). Kredit Tanpa 
Agunan. Diakses pada October 19, 2018, Diperoleh dari www.Cermati.com:

https://www.cermati.com/artikel/me ngenal-riba-dan-kaitannya-denganbunga-bank

Christiawan, R. (2019, March 9). My Article Tanggung Jawab Endorser. Diakses Pada May 17, 2019, swa online magazine, Diperoleh dari : https://swa.co.id/swa/myarticle/tanggung-jawab-endorser

Dana Aditiasari. (2016, Mei 12). Properti. Januari 10, 2019, Diperoleh dari: finance.detik.com: https://finance.detik.com/properti/d3209063/kpr-syariah-masih-minimini-alasannya

Daymon, C., \& Holloway, I. (2011). Qualitative Research Methods in Public Relations and Marketing Communications (2 ed.). New York, United States of America: Routledge Taylor \& Francis Group.

Fauzian, R. (2020, Januari 09). Properti Syariah Mulai Dilirik Konsumen. Retrieved Agustus 31, 2020, from Medcom.id:

https://www.medcom.id/properti/ne ws-properti/yKXGvG9k-propertisyariah-mulai-dilirik-konsumen

Kampung Tahfidz Jatiluhur. (n,d). Investasi Properti yang Menguntungkan Dipadukan dengan Kebun yang Produktif Di Kawasan Wisata yang Indah Waduk Jatiluhur. Diakses pada may 17, 2019, Di Peroleh dari : Kampung Tahfidz Jatiluhur: https://kampungtahfidzjatiluhur.com !

Khoirunisa, I. (2016, June 9). Tertarik Beli Rumah Syariah? Pelajari Dulu Konsepnya. Di Akses pada October 19, 2018, Di Peroleh dari :

www.rumah.com:

https://www.rumah.com/berita- properti/2016/6/127585/tertarikbeli-rumah-syariah-pelajari-dulukonsepnya

Kotler, P., Amstrong, G., \& Opresnik, M. O. (2018). Principles of Marketing (7 ed.). Harlow, United Kingdom : Pearson Education Limited.

Kotler, P., \& Keller, K. L. (2016). Marketing Management 15 Global Edition. Edinburgh Gate, England: Pearson Education Limited.

Latief. (2014, April 01). Property Syariah Makin Diperhitungkan. Di Akses pada October 21, 2018, Di peroleh dari properti.kompas.com: https://properti.kompas.com/read/20 16/04/01/183200921/Properti.Syaria h.Makin.Diperhitungkan.

Littlejohn, S. W., \& Foss, K. A. (2016). Ensiklopedia Teori Komunikasi. Jakarta: Kencana.

Majelis Ulama Indonesia. (2004). mui.or.id. Diakses pada 16 January 2019, Diperoleh dari : www.mui.or.id: https://mui.or.id/wpcontent/uploads/2017/02/32.-BungaInterestFaidah.pdf

Muhammad. (2018). Bisnis Syariah: Transaksi dan Pola Pengikatannya. Depok: PT RajaGrafindo Persada.

Mulyo, P. D. (2016). Endorser Sebagai Affirmative Action Dalam Komunikasi Bisnis . Jurnal Nomosleca . Diperoleh dari : http://jurnal.unmer.ac.id/index.php/n /article/view/621

Pawito, P. (2007). Penelitian Komunikasi Kualitatif. Yogyakarta: LKiS Yogyakarta.

Priyono. (2008). Metode Penelitian Kuantitatif. Sidoarjo: Zifatama.

Pinariya, J. M., \& Pracillia, E. (2014). Celebrity Endorsement on Attitude 
Formation of Brand Shampoo: Research on Middle Class Consumer, Jakarta. Jurnal Ilmu Komunikasi , 2, 5-6, ISSN: 2338431X, Diperoleh dari: https://journal.budiluhur.ac.id/index. php/avantgarde/search/authors/view ?firstName $=$ Janette $\&$ middleName $=$ M.\&lastName $=$ Pinariya\&affiliation $=\&$ country $=\mathrm{ID}$

Quthb, S. (2018). Tafsir Ayat-Ayat Riba: Mengupas Persoalan Riba Sampai Ke Akar-akarnya. Jakarta: Wali Pustaka.

Schiffman, L. G., \& L.Wisenblit, J. (2015). Consumer Behavior ( 7 ed.). Edinburgh Gate, England : Pearson Education Limited

Sindonews.com. (2015, Februari 12). All About That BUZZ: The Power of Brand Endorsement or Build-in Branding. Diakses pada : May 17, 2019, Diperoleh dari Sindo News : https://ekbis.sindonews.com/read/96 3405/150/all-about-that-buzz-thepower-of-brand-endorsement-orbuild-in-branding-1423709543

Soliha, E. (2011). Pengaruh Kredibilitas Sumber dan Rerangka Pesan Pada Persepsi Risiko Konsumen. Jurnal Manajemen Teori dan Terapan , 2-3. Diperoleh dari : https://ejournal.unair.ac.id/JMTT/article/vie w/2422

Sugiyono. (2016). Memahami Penelitian Kualitatif. Bandung: Alfabeta.

Suherman, M. (2016, February 19). OPINI Mata Air dan Air Mata Seleb
Endorser. Diakses pada : May 17, 2019, Diperoleh dari : liputan6.com: https://www.liputan6.com/showbiz/r ead/2440170/opini-mata-air-dan-airmata-seleb-endorser

Sumardy, Silviana, M., \& Melone, M. (2011). The Power of Word Of Mouth Marketing . Jakarta: PT Gramedia Pustaka Utama.

Suyanto, M. (2018). Muhammad Marketing Strategy: Strategi Pemasaran Ala Nabi Muhammad SAW. Yogyakarta: Andi Offset.

Tempo.co. (2017, 08 24). BISNIS. Diperoleh 11 13, 2018, dari : bisnis.tempo.co : https://bisnis.tempo.co/read/902993/ penjualan-properti-terus-naikhingga-2018-termasukapartemen/full\&view=ok

(IMAM HAMDI)

Thomson Reuters. (2018). Islamic Finance Development Report 2018 Building Momentum. Thomson Reuters. Thomson Reuters.

Viva.co.id. (nd). Profil Syeikh Ali Saleh Muhammad Ali Jaber. (diakses pada tanggal berapa) Diperoleh dari : https://www.viva.co.id/siapa/read/12 5-syekh-ali-jaber

Waluya, B. (2009). Sosiologi Menyelami Fenomena Sosial Di Masyarakat. PT Setia Purna Inves.

Word of Mouth Marketing Association. (n.d.). Diakses pada : Mei 2, 2019 Home: Womma Pedia.: Womma Pedia: Diperoleh dari: http://wommapedia.org/ 